v. 01, n. 02 : pp.043-057, 2005

ISSN $1808-0448$

D.O.I.: $10.3895 /$ S $1808-04482005000200004$
Revista Gestão Industrial

\section{AUDITORIA DE SEGURANÇA E SAÚDE DO TRABALHO EM UMA INDÚSTRIA DE ALIMENTOS E BEBIDAS}

\author{
SAFETY AND HEALTH AUDIT IN THE WORKPLACE \\ AT A BEVERAGE AND FOOD MANUFACTURING PLANT
}

Cristiana de Aquino Lacerda ${ }^{1}$; Carlos Eduardo Pinheiro Chagas ${ }^{2}$; Cleber Carvalho Barbosa ${ }^{3}$ J João Vicente Dias Cabrera ${ }^{4}$; Jordana Vinagre de Farias ${ }^{5}$

${ }^{1}$ UFRJ, Rio de Janeiro, cal@uninet.com.br ${ }^{2}$ UFRJ, Rio de Janeiro, eduardo.chagas@terra.com.br ${ }^{3}$ UFRJ, Rio de Janeiro, cleber.barbosa@ae.ge.com ${ }^{4}$ UFRJ, Rio de Janeiro, jvdcabrera@yahoo.com.br ${ }^{5}$ UFRJ, Rio de Janeiro, jordana.farias.jf@bayer.com.br

Recebido para publicação em: 20/02/2005 Aceito para publicação em: 28/06/2005

\title{
RESUMO
}

Este trabalho apresenta um estudo sobre as condições de segurança e saúde do trabalho em uma fábrica de pequeno porte do setor de alimentos e bebidas no Rio de Janeiro. Por meio de inspeções, entrevistas com supervisores e funcionários e avaliações qualitativas, foram identificados os setores prioritários para análise de riscos ocupacionais: físicos, químicos, biológicos, ergonômicos $e$ de acidentes. Foram objeto de análises específicas as instalações prediais e de conforto para funcionários, os sistemas de proteção e combate a incêndios e os riscos físicos e ergonômicos do processo industrial, observando-se as normas regulamentadoras pertinentes. Foram apresentadas conclusões e recomendações visando sua transformação em um ambiente seguro.

Palavras-chave: Segurança, qualidade de vida, riscos ocupacionais.

\section{Introdução}

Segundo o Anuário Brasileiro de Proteção (2004), o Estado do Rio de Janeiro foi um dos expoentes nas últimas estatísticas de acidentes de trabalho apresentando um aumento de cerca de $35 \%$ no total de acidentes de trabalho e de quase $45 \%$ do total de doenças do trabalho. A indústria de produtos alimentares e de bebidas ocupa a sexta posição em acidentes de trabalho registrados segundo o setor de atividade econômica (2000/2002).

O aumento do número de acidentes e fatalidades do trabalho são decorrentes das más condições e da insegurança dos ambientes de trabalho aliadas à falta de fiscalização por parte dos órgãos competentes. O cumprimento à legislação de segurança e saúde do trabalho — as Normas Regulamentadoras do Ministério do Trabalho e Emprego (NRs) - é um desafio para a maioria das 
empresas que, em geral, priorizam as melhorias da qualidade do produto em detrimento de melhores condições ambientais de trabalho.

Ao verificar-se a regulamentação de produção de bebidas (Lei $\mathrm{n}^{\circ}$ 8.918/94) e de alimentos (Portaria $\left.n^{\circ} 326 / 97\right)$, que estabelecem requisitos essenciais de higiene e de fabricação, do cultivo da matéria-prima até o transporte dos produtos finais, percebe-se a importância dada não somente à qualidade do produto como também ao conforto e segurança do ambiente de trabalho.A empresa, ao atender às necessidades de bem-estar de seus empregados, tornando-os saudáveis e participativos, diminui seus custos operacionais, aumentando sua produtividade, seus lucros e a qualidade de seus produtos - fator fundamental no mercado competitivo para satisfazer as exigências dos consumidores.

\section{Objetivo e metodologia adotada}

Este estudo teve por objetivo a verificação das condições de trabalho em uma fábrica de alimentos e bebidas de pequeno porte presente no mercado há 25 anos. A empresa tem um efetivo fixo de 114 funcionários. O horário de trabalho é de 6:00 às 17:00 horas.

A realização do trabalho teve por base: as NRs, as Normas de Higiene Ocupacional (NHO) da Fundação José Duprat Figueiredo de Segurança e Medicina do Trabalho (Fundacentro) e as normas da Associação Brasileira de Normas Técnicas (ABNT). Em situações não encontradas na legislação brasileira, foram adotadas as recomendações da American Conference of Governmental Industrial Hygienists (ACGIH), da Ocupational Safety and Health Administration (OSHA) e do National Institute of Safety and Health.

A metodologia empregada consistiu nos seguintes passos: elaboração de layout de todos os setores da empresa; descrição dos processos de trabalho; exame da documentação relativa à segurança e saúde do trabalhador; entrevistas com diretor, supervisores e funcionários sobre as rotinas de trabalho; elaboração de listas de verificação para avaliação dos ambientes em relação às NRs; inspeção e registro fotográfico dos locais de trabalho; elaboração de matriz de relevância para classificação dos riscos prioritários; realização e análise de medições quantitativas dos riscos; conclusões e propostas de melhoria.

\section{Descrição dos processos de fabricação}

\subsection{Fabricação dos biscoitos de polvilho}

O processo se inicia com o transporte da matéria-prima à sala de preparo da massa onde os ingredientes são conferidos, pesados e misturados. É feita a formatação e distribuição automática da 
massa em tabuleiros que são levados aos fornos rotativos. Os biscoitos são resfriados em temperatura ambiente e ensacados em embalagens plásticas para posterior envase (Figura 1).

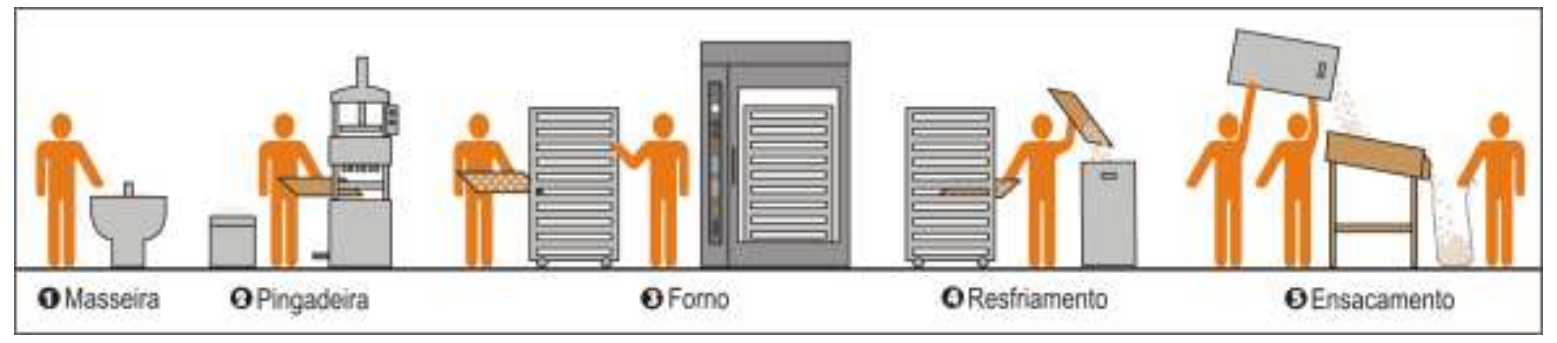

Figura 1 - Linha de produção do biscoito de polvilho

\subsection{Fabricação da pipoca doce}

O processo se inicia com o transporte da matéria-prima à área de produção utilizando o monta-carga. Os ingredientes são colocados em fornos, do tipo canhão, para promover o estouro da pipoca que cai diretamente em silos de aço inox. Sob este silo, encontra-se uma peneira vibratória que seleciona os melhores tamanhos e retira possíveis contaminantes. A pipoca é torrada e caramelizada em drajadeiras (forno), resfriada em temperatura ambiente e ensacada para posterior envase (Figura 2).

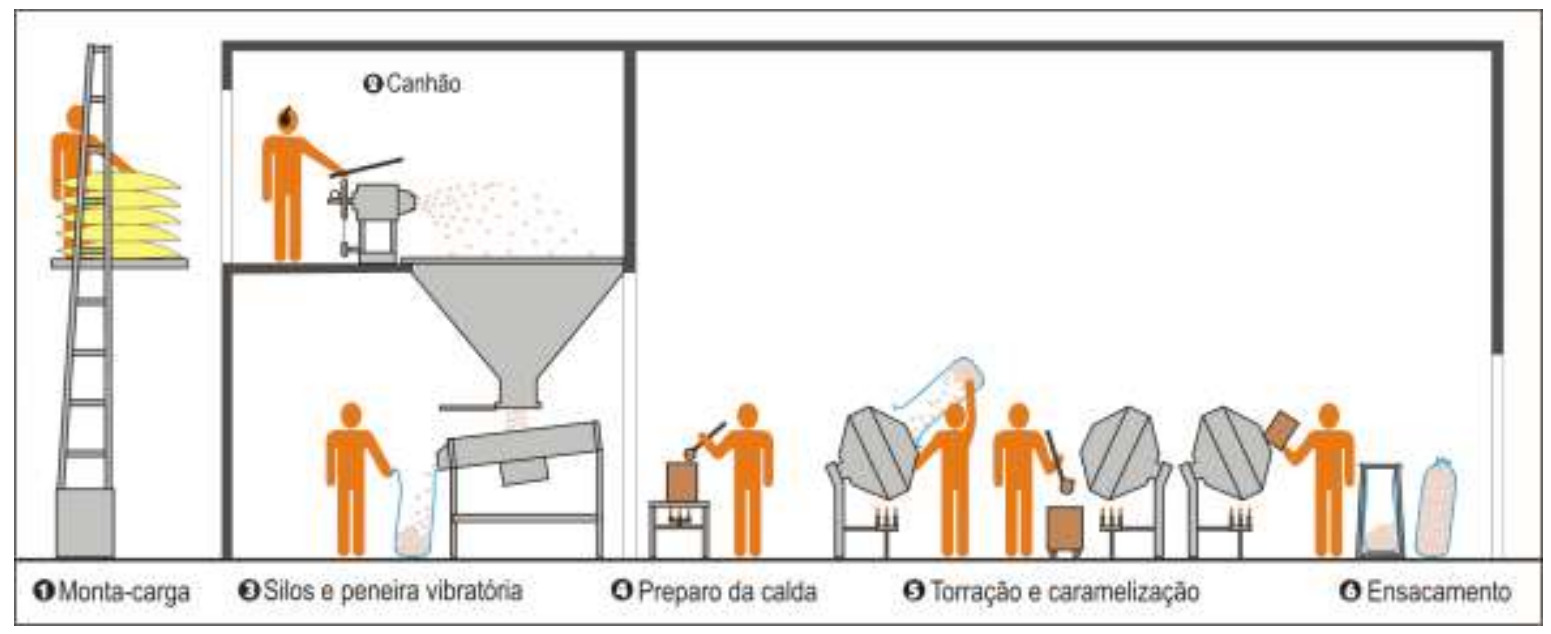

Figura 2 - Linha de produção da pipoca doce crocante

\subsection{Fabricação dos biscoitos salgadinhos de milho}

Os ingredientes são misturados, colocados na máquina extrusora onde são formatados e enviados ao secador rotativo para serem saborizados. Os biscoitos são ensacados para posterior envase (Figura 3). 


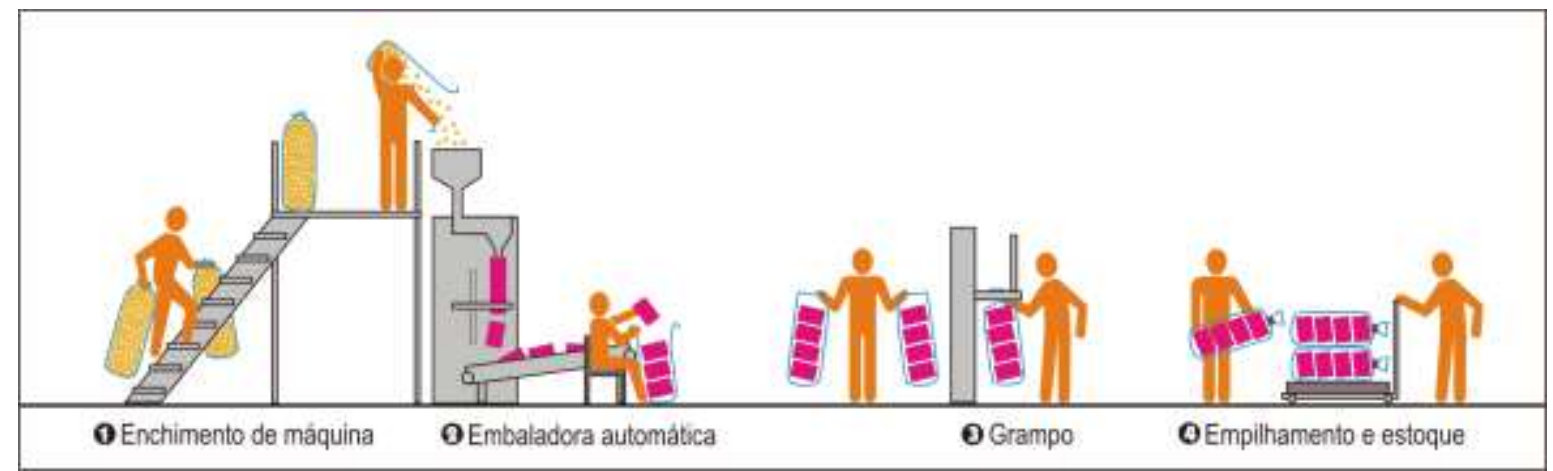

Figura 3 - Linha de produção dos salgadinhos de milho

\subsection{Empacotamento dos produtos alimentícios}

Os biscoitos são despejados em máquinas automáticas de embalagem plástica (sem contato manual). As embalagens soltas caem em esteiras rolantes. As embaladoras contam os pacotes e, manualmente, os colocam dentro de sacos para serem grampeados e paletizados. Em seguida, os paletes são levados por carrinhos manuais para armazenamento no estoque (Figura 4).

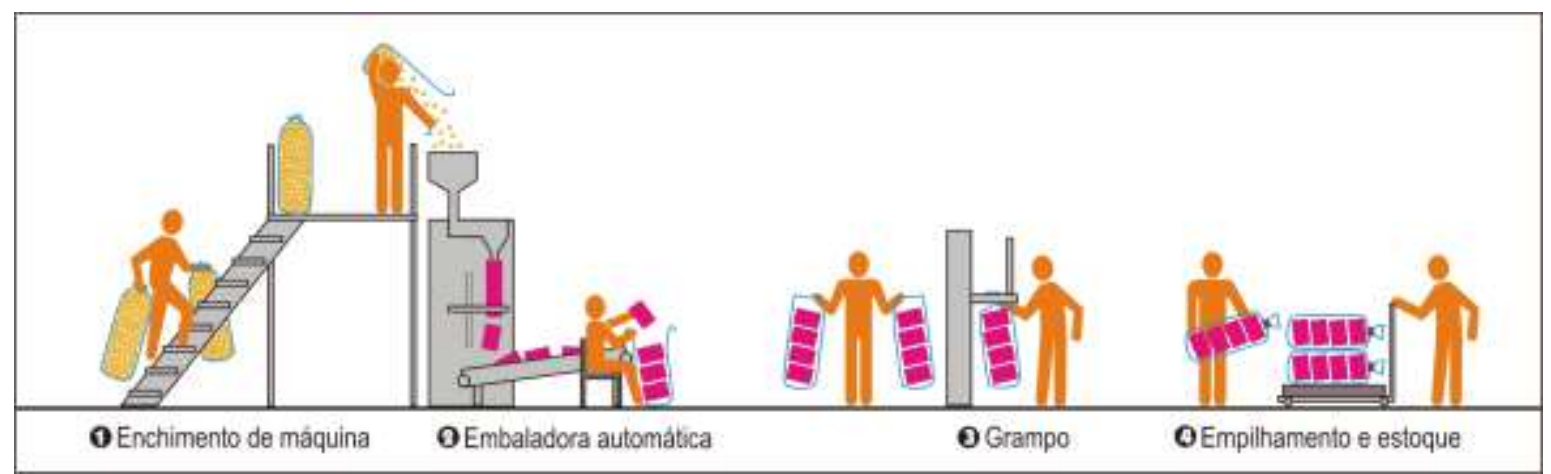

Figura 4 - Empacotamento dos produtos alimentícios

\subsection{Fabricação de bebidas}

A produção se inicia com um sistema de filtragem da água. A seguir, é feita a mistura dos ingredientes que segue para os tanques de pasteurização. A bebida é direcionada para o tanque pulmão e depois, por gravidade, para as máquinas de envase automático. Os copos, lacrados e datados, seguem por uma esteira rolante até o setor de embalagem onde são acondicionados manualmente em caixas que em seguida serão fechadas por seladora automática. As caixas são empilhadas em paletes, embaladas automaticamente em filme stretch e paletizadas (Figura 5). 


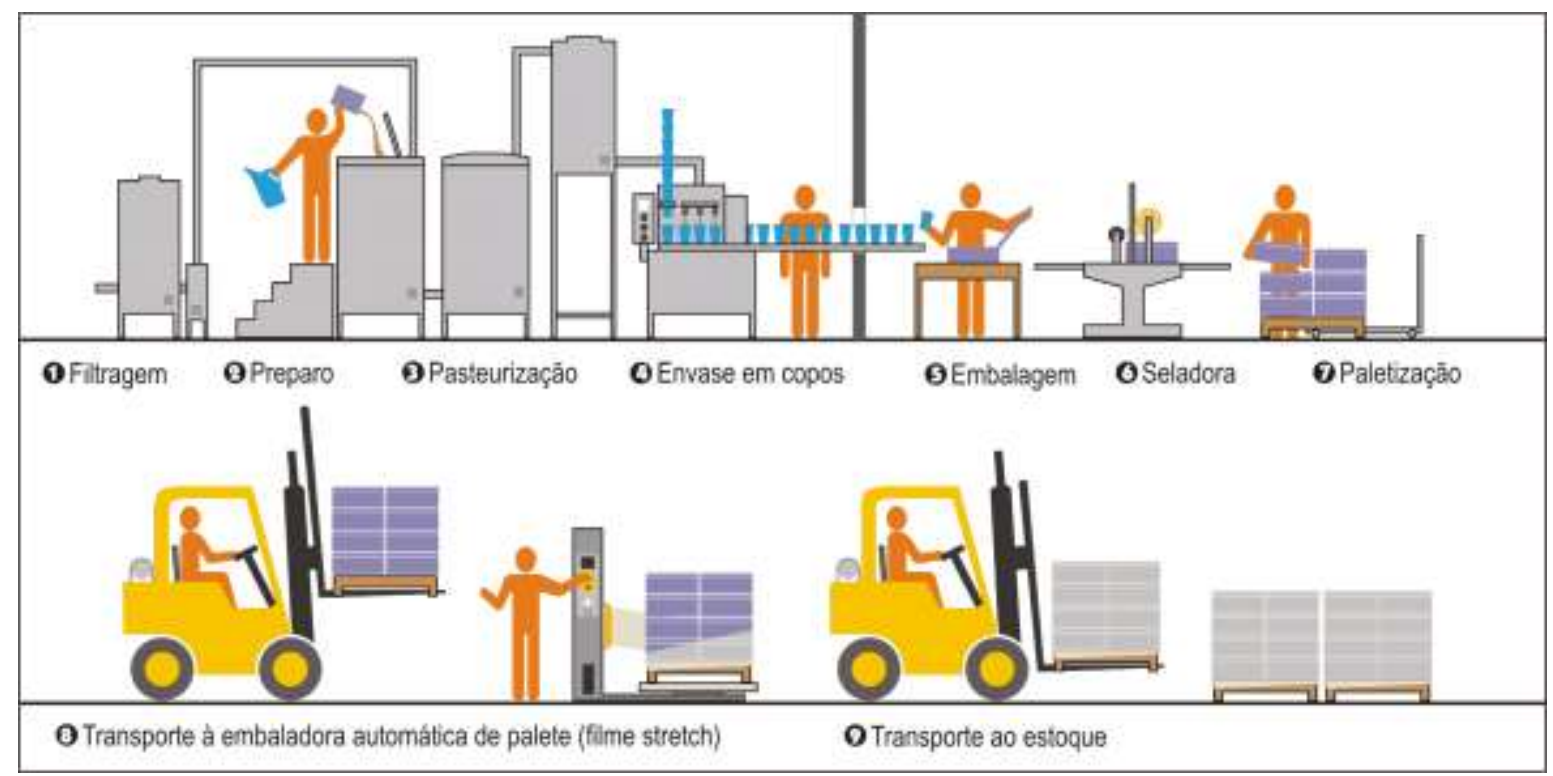

Figura 5 - Linha de produção de bebidas

\section{Estruturação da segurança}

Há uma grande deficiência na elaboração de ordens de serviço relativas aos procedimentos de operação dos equipamentos e às normas de segurança do trabalho para os funcionários das empresas terceirizadas. É importante divulgar os procedimentos de segurança tanto para os funcionários da empresa como para os terceirizados. Vale lembrar que a empresa é co-responsável, como contratante, na implementação de medidas preventivas de acidentes e de doenças do trabalho para todos os trabalhadores do estabelecimento, independentemente de serem funcionários da empresa.

Outro aspecto que tem prejudicado a empresa durante as fiscalizações é a falta de organização da documentação obrigatória que deve estar reunida e acessível aos profissionais de recursos humanos, produção, segurança e medicina do trabalho.

\subsection{SESMT}

Segundo a norma, para o dimensionamento do Serviço Especializado em Engenharia de Segurança e Medicina do Trabalho (SESMT) da empresa, faz-se necessário um técnico de segurança do trabalho contratado para realizar treinamentos admissionais, periódicos, palestras educativas e de conscientização, organizar a Comissão Interna de Prevenção de Acidentes (CIPA) e promover a Semana Interna de Prevenção de Acidentes.

Atualmente, a empresa não possui SESMT próprio e utiliza os serviços do técnico de segurança de uma prestadora de serviços. Não há nenhum treinamento para os funcionários da empresa e 
nenhuma qualificação é exigida nas contratações. Os funcionários podem ser relocados de uma função para outra em épocas de sazonalidade. A rotatividade é alta para alguns cargos menos qualificados.

A CIPA da gestão atual (2003/2004) não possui atuação efetiva. Não há registro de eleições para representantes dos empregados e nem de formação da comissão eleitoral. $O$ fato de não haver CIPA atuante dificulta o atendimento do objetivo que é a compatibilização permanente do trabalho com a preservação da saúde dos trabalhadores.

\subsection{Equipamento de Proteção Individual (EPI)}

A forma de aquisição dos EPIs se dá somente pela pesquisa de preço no mercado, o que não garante sua eficácia. Cada funcionário recebe seu EPI quando ingressa na empresa, assina um registro de recebimento, porém não recebe treinamento. Durante as inspeções, observou-se que alguns EPIs obrigatórios não são fornecidos pela empresa. Os supervisores por cada setor não exigem a utilização dos EPIs, embora seja norma da empresa e de conhecimento de todos os funcionários.

Observou-se também o excesso de poeira orgânica no ar. Seria muito importante um estudo para exaustão no ambiente para diminuir o índice da poeira em suspensão. Segundo informações obtidas, nenhum exaustor da fábrica funciona de modo eficaz. Recomenda-se a fiscalização da utilização das máscaras de proteção respiratória que se encontram disponíveis na empresa.

\subsection{Programa de Controle Médico de Saúde Ocupacional (PCMSO)}

Para atender às normas, a empresa contratou há quatro anos, os serviços prestados de um médico do trabalho para coordenar, elaborar e implementar o PCMSO. O programa foi elaborado apenas para fins de fiscalização. Foram realizadas entrevistas informais com os trabalhadores que permitiram concluir que os exames previstos nunca foram realizados e que não há nenhum programa de educação para a saúde.

\subsection{Programa de prevenção de riscos ambientais (PPRA)}

As normas estabelecem a obrigatoriedade da elaboração e implementação do PPRA por parte dos empregadores, visando a preservação da saúde e da integridade dos trabalhadores, por meio da antecipação, reconhecimento, avaliação e controle dos riscos existentes ou que possam vir a existir no ambiente de trabalho. 
A empresa forneceu, para análise, o último PPRA realizado em 2003 por técnico prestador de serviço. No PPRA da empresa, os riscos identificados e as medidas de controle estão incompletos, mal detalhados e alguns nem mesmo existem. Não foram disponibilizados, para esta análise, os resultados de exames periódicos que possam existir e que forneceriam os dados necessários para comprovar possíveis doenças laborais. A empresa também não apresentou as avaliações quantitativas e nem os programas de controle dos riscos existentes.

\section{Levantamento de dados}

Como parte dos trabalhos, foram identificados os riscos existentes e sua localização em cada setor da empresa. Foi realizada a Matriz de Relevância (Quadro 1) que permitiu priorizar os fatores que prejudicam a segurança e saúde dos empregados.

\begin{tabular}{|c|c|c|c|c|c|c|c|c|c|c|c|c|c|c|c|}
\hline \multicolumn{2}{|l|}{ EMPRESA } & \multicolumn{12}{|c|}{ RISCOS } & \multirow[b]{2}{*}{$\mathbf{f}_{\mathrm{S}}$} & \multirow[b]{2}{*}{$\%$} \\
\hline SETORES & 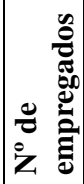 & 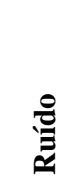 & 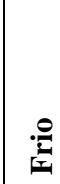 & $\frac{\grave{0}}{\tilde{\pi}}$ & 默 & 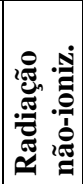 & : & 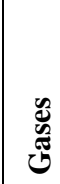 & 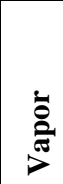 & 异 & 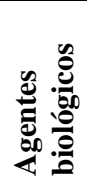 & 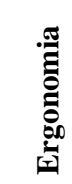 & 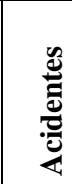 & & \\
\hline Refeitório & 1 & 3 & 0 & 3 & 9 & 0 & 0 & 1 & 0 & 0 & 1 & 3 & 3 & 23 & $1 \%$ \\
\hline Administração & 7 & 3 & 0 & 0 & 9 & 0 & 0 & 0 & 0 & 0 & 0 & 3 & 1 & 112 & $4 \%$ \\
\hline Rec. Humanos & 11 & 3 & 0 & 0 & 9 & 0 & 0 & 0 & 0 & 0 & 0 & 3 & 3 & 198 & $7 \%$ \\
\hline Manutenção & 2 & 3 & 0 & 3 & 3 & 1 & 3 & 0 & 1 & 0 & 0 & 3 & 3 & 40 & $1 \%$ \\
\hline Depósito & 1 & 9 & 0 & 3 & 3 & 0 & 3 & 0 & 1 & 0 & 0 & 3 & 9 & 31 & $1 \%$ \\
\hline Polvilho & 10 & 9 & 0 & 9 & 1 & 0 & 3 & 0 & 0 & 0 & 0 & 9 & 3 & 340 & $12 \%$ \\
\hline Pipoca & 13 & 9 & 0 & 9 & 9 & 0 & 9 & 1 & 0 & 0 & 0 & 9 & 9 & 715 & $26 \%$ \\
\hline Milho & 2 & 9 & 0 & 9 & 1 & 0 & 1 & 1 & 0 & 0 & 0 & 3 & 3 & 54 & $2 \%$ \\
\hline Bebidas & 5 & 9 & 0 & 0 & 9 & 0 & 0 & 0 & 0 & 1 & 0 & 3 & 3 & 125 & $4 \%$ \\
\hline Embalagem & 29 & 9 & 0 & 3 & 1 & 0 & 1 & 0 & 0 & 0 & 0 & 9 & 3 & 754 & $27 \%$ \\
\hline Estoque & 1 & 9 & 0 & 1 & 1 & 0 & 0 & 0 & 0 & 0 & 0 & 1 & 3 & 15 & $1 \%$ \\
\hline Transporte & 32 & 1 & 0 & 3 & 0 & 0 & 1 & 1 & 0 & 0 & 0 & 3 & 3 & 384 & $14 \%$ \\
\hline $\mathbf{f}_{\mathbf{A}}$ & 114 & 644 & 0 & 421 & 384 & 2 & 219 & 48 & 3 & 5 & 1 & 652 & 412 & 2791 & $\begin{array}{c}100 \\
\%\end{array}$ \\
\hline$\%$ & - & $23 \%$ & $0 \%$ & $15 \%$ & $14 \%$ & $0 \%$ & $8 \%$ & $2 \%$ & $0 \%$ & $0 \%$ & $0 \%$ & $23 \%$ & $15 \%$ & $100 \%$ & - \\
\hline
\end{tabular}

Valores: 0 (zero), sem exposição ao agente de risco; 1 (um), sem atuação perceptível do agente; 3 (três), quando a exposição àquele agente se encontra abaixo do nível de ação; e 9 (nove), quando a exposição ao agente de risco se encontra acima do limite de tolerância.

Quadro 1 - Matriz de relevância

A Matriz de Relevância demonstra que os riscos com os maiores percentuais são os físicos, ergonômicos e de acidentes. Observa-se que ruído e ergonomia apresentam igual valor de $23 \%$ da exposição total de riscos; acidentes e calor representam, cada um, 15\%; e iluminação, $14 \%$ do total. Os setores mais afetados são os de embalagem com uma taxa de $27 \%$, seguido pelo setor de produção de pipoca (26\%), de transporte (14\%) e de fabricação do biscoito de polvilho (12\%). 
Esses dados indicaram o caminho para uma avaliação quantitativa dos riscos: medições de ruído, temperatura, velocidade do ar, nível de iluminação e esforço físico em equipamentos; análise de tarefas; inspeção das instalações elétricas e das proteções contra incêndio. A verificação das características ambientais foi realizada utilizando-se equipamentos de medições e normas específicas para cada análise. A partir deste estudo, foram feitas recomendações visando a correção dos problemas.

\subsection{Condições de iluminamento}

Verificou-se que a iluminação geral não é uniformemente distribuída e difusa. Foram encontrados níveis de iluminamento abaixo dos valores estabelecidos pelas normas técnicas e legais. As áreas que precisam de melhorias são: escritórios, refeitório, manutenção, produção de pipoca e bebidas. Há que se destacar uma boa prática na empresa: a exploração da iluminação natural por meio de telhas translúcidas.

\subsection{Conforto térmico}

Segundo relato dos trabalhadores, na área dos canhões de pipoca já, foram presenciados oito desmaios, em um período de cinco anos, com pessoas de sexo masculino, na faixa de 25 a 30 anos. Igual problema também acontece na área das drajadeiras, porém com pessoas do sexo feminino, na faixa etária de até 40 anos. Os trabalhadores estão expostos a níveis de temperatura acima dos limites de tolerância para exposição ao calor.

\subsection{Conforto acústico - Nível de Pressão Sonora (NPS)}

Observou-se que em todas as áreas de produção, os valores medidos encontram-se acima do limite de tolerância ou acima do nível de ação, que também requer cuidados. Não há um estudo que avalie a minimização do ruído através da interferência no processo produtivo, tais como enclausuramento de máquinas ou motores. $\mathrm{Na}$ área dos canhões de pipoca, pode-se observar índices sensivelmente elevados e incômodos, que foram objeto de reclamação por parte de moradores da vizinhança. É particularmente interessante um estudo para o isolamento acústico nesse setor. Somente os operadores de canhões utilizam protetor auricular tipo concha, porém não há comprovação de sua eficácia. 


\subsection{Transporte, movimentação, armazenagem e manuseio de materiais}

Verificou-se que o monta-carga não tem proteção contra quedas e que os funcionários o utilizam para seu próprio deslocamento junto com a carga. Esta prática incorreta pode acarretar em acidente de queda, pois o equipamento não é apropriado para transportar pessoas. Nesse mesmo equipamento não foram verificadas inspeções periódicas, apenas inspeções corretivas nos cabos de aço e roldanas.

Os carrinhos manuais de movimentação de carga não têm proteção para as mãos e para evitar impacto contra obstáculos e são utilizados como "patinete" podendo gerar acidentes de queda e de atropelamento. Não há demarcação nos pisos dos depósitos delimitando o tráfego de empilhadeiras e nem afastamento de segurança demarcado entre os materiais empilhados e as estruturas laterais do prédio. Essa prática dificulta o combate a princípios de incêndio, devido à impossibilidade de locomoção entre os paletes.

Atenção especial deve ser dada à frota de veículos, composta de duas empilhadeiras e dez caminhões, pois na estatística mundial tem uma considerável participação no elevado número de acidentes envolvendo a movimentação de materiais. As irregularidades encontradas na empresa quanto a esse item foram: operador de empilhadeira e motoristas sem cartão de identificação; funcionários não realizam exames periódicos; falta de inspeções e manutenções periódicas na frota; empilhadeira com os quatro pneus em mau estado, vazamento de água e óleo, farol quebrado e desprovida de buzina, cinto de segurança e luz de sinalização de marcha a ré. Não há programa de segurança no trânsito e nem pré-requisitos para a aquisição de veículos. Segundo relato de funcionários, até hoje, só aconteceram dois acidentes de trânsito envolvendo veículos a serviço da empresa, ocasionando o afastamento de um funcionário e um acidente fatal.

\subsection{Máquinas, ferramentas e equipamentos — condições de operação}

Durante as visitas realizadas foi constatado que:

- a maioria das máquinas não possui botão de emergência e nem dispositivos de segurança que evite o acionamento acidental durante a tarefa;

- o acesso ao acionamento das drajadeiras é difícil devido à sua posição;

- falta de proteção nas drajadeiras, canhões, compressores, exaustores, transmissões da extrusora, monta-carga, embaladoras, masseira e dosificadora de tempero expondo os trabalhadores a acidentes graves em engrenagens;

- falta de cuidado dos empregados quanto à conservação e limpeza dos locais de trabalho que diminuiriam os riscos provenientes de graxas, óleos e outras substâncias que tornam os pisos 
escorregadios. Isso provavelmente decorre da falta de supervisão da empresa na manutenção das condições ideais de trabalho;

- o vaso de pressão não atende às determinações da legislação. Sua válvula de segurança não é verificada periodicamente e está com a calibração vencida. O manômetro também não é inspecionado e não tem certificado de calibração, com o objetivo de garantir a confiabilidade de sua medição. Não são realizadas inspeções de segurança nesses equipamentos. Esse item, inclusive, é passível de penalidade de interdição pelo órgão competente;

- a oficina mecânica está mal iluminada e com o piso constantemente molhado, aumentando o risco de acidentes. Foram encontrados diversos equipamentos na oficina, tais como: furadeira de coluna, esmeril, guilhotina, escada, prensa hidráulica, lixadeira e outros materiais em mau estado de conservação e operação.

\subsection{Riscos em eletricidade, equipamentos e instalações elétricas}

A vistoria das instalações foi iniciada na subestação de energia elétrica. A informação obtida é a de que uma empresa terceirizada é responsável pela manutenção da subestação apesar de não existir um contrato formal entre as partes. A prestação de serviço acontece quando ocorre algum problema ou em caso de reformas. Não foi evidenciado nenhum tipo de identificação, tais como placas indicativas ("Perigo - Alta Tensão"), sistema de identificação por cores, níveis de tensão ou corrente, diagrama unifilar ou projeto. Também não foi identificado nenhum sistema de proteção, alarme e nem mesmo procedimentos de emergência para o caso de acidente neste local.

A verificação elétrica foi similar em todas as áreas no que tange às sinalizações, instalações elétricas ou serviços prestados, com exceção do setor de bebidas que possui equipamentos mais modernos. As instalações da fábrica, de maneira geral, seguem as observações abaixo descritas:

- não há sinalização nos quadros elétricos que se encontram sujos e engordurados;

- a instalação elétrica aérea da fábrica é feita através de eletrocalhas abertas e várias instalações não possuem condutores;

- não foi evidenciado nenhum controle de identificação dos condutores;

- não há uma oficina apropriada para a execução dos serviços;

- segundo informações do eletricista, existe no leito aéreo um alimentador aterrado circuncidando a fábrica, funcionando como aterramento, porém não foi evidenciado que ele esteja dentro das características exigidas pela norma;

- em alguns locais, os condutores elétricos estão amarrados com arames nas instalações metálicas das paredes e nos equipamentos; 
- foi evidenciada a presença de quadros elétricos em processo de oxidação, tomadas e interruptores expostos, bem como quadros elétricos sem tampa de proteção;

- as luminárias não seguem um padrão de instalação, são distribuídas nas linhas de produção e, em alguns locais, estão penduradas com cordas ou fios elétricos amarrados às estruturas metálicas (calha) e não possuem proteção contra explosão;

- não foi evidenciada a presença de pára-raio na edificação (somente na subestação);

- existem ligações simultâneas de mais de um aparelho à mesma tomada;

- não se obteve nenhuma informação com relação às características (fichas de registro) dos transformadores, capacitores, motores elétricos, dentre outros.

\subsection{Condições da construção}

Foram detectadas várias falhas, demonstrando não-conformidade às normas, que devem ser corrigidas com urgência: aberturas sem qualquer proteção contra queda de altura; escadas sem corrimão; ausência de elemento antiderrapantes; piso da circulação com saliências que podem causar acidentes; falta de sinalização de alerta destacando o desnível do piso; telas de proteção de janelas e aberturas em mau estado de conservação permitindo a entrada de pequenos animais e pragas; caixas d'água com tampa quebrada que podem causar contaminação de pessoas e de produtos; restos de materiais e utensílios espalhados; iluminação e ventilação deficientes; e paredes sujas.

\section{Ergonomia}

De acordo com a matriz de relevância (Quadro 1), três postos de trabalho foram priorizados para análise: operador de canhão de pipoca, operador de pingadeira e embaladora de produtos alimentícios. Os problemas foram identificados por meio de registro de imagens (fotos e filmagem) e entrevistas com a equipe. Como ferramenta de auxílio na investigação ergonômica, foi utilizado o Rapid Upper Limb Assessment Tool (RULA) — método de pesquisa que avalia a carga biomecânica e postural do corpo com atenção particular às regiões do pescoço, tronco e membros superiores.

\subsection{Operador de canhões de pipoca}

$\mathrm{Na}$ área dos canhões da pipoca, quatro funcionários têm a tarefa de promover o estouro do milho. O ambiente mal iluminado, o ruído de impacto (400 estouros por dia), o calor excessivo e a 
poeira do milho contribuem para o desconforto do trabalhador nesse setor. Verificou-se que os funcionários não usam os protetores auriculares corretamente e que estes se encontram desgastados. A tarefa também exige bastante esforço físico. Os principais problemas observados foram: inexistência de pausas para descanso, falta de treinamento sobre carregamento de peso, trabalho em pé durante toda a jornada de trabalho, falta de conforto para os funcionários (longa distância a percorrer para ir ao sanitário ou obter água potável), risco de acidente devido à falta de proteção dos equipamentos e risco de queda de altura decorrente da falta de proteção da edificação.

\subsection{Operador de pingadeira do biscoito de polvilho}

A tarefa consiste em operar a máquina pingadeira - equipamento (acionado por pedal mecânico) utilizado para formatação e distribuição automática da massa de biscoito de polvilho em tabuleiros. Os principais problemas são o esforço necessário para acionamento do pedal e o trabalho em pé, durante toda a jornada de trabalho, que ocasionam dores lombares, nos joelhos e nas pernas.

\subsection{Embaladora de produtos alimentícios}

As máquinas são muito antigas, desgastadas e apresentam defeitos constantemente, exigindo a presença de três funcionários para o reparo imediato a fim de minimizar o problema causado pela interrupção da produção. O nível de ruído medido foi de $90 \mathrm{~dB}(\mathrm{~A})$. As operadoras não utilizam o protetor auricular fornecido pela empresa. A norma permite, no máximo, um nível de ruído de $85 \mathrm{~dB}(\mathrm{~A})$ para oito horas de trabalho sem EPI.

A tarefa das embaladoras é monótona e repetitiva com grau mínimo de dificuldade, mas sem possibilidade de desligamento mental devido à atenção na contagem dos pacotes. Dentre os processos de fabricação da empresa, é o único realizado na posição sentada. Pode parecer confortável, mas permanecer sentada por muito tempo esgota da mesma forma. As funcionárias costumam improvisar encostos com papelão para diminuir o desconforto da cadeira que não possui regulagem de altura lombar e de assento para se adequar às características físicas de cada trabalhadora, como determina a norma.

\section{Proteção contra incêndios e explosões}

De acordo com o Código de Segurança contra Incêndio e Pânico, a empresa está classificada com grau de risco médio. Avaliando pelos critérios das normas pertinentes, calcula-se que são necessários 59 extintores para adequação às exigências legais. Atualmente, a empresa 
possui apenas 13 extintores, sem fichas de controle de inspeção mensal, que também não é realizada. Observou-se, em todas as visitas, que os extintores são frequientemente obstruídos por caixas, bandejas, plásticos e outros materiais, por falta de orientação aos trabalhadores. A maioria dos extintores está com a recarga vencida e com os pinos retirados. Não foram encontradas evidências de que os extintores sejam pesados semestralmente com o objetivo de serem recarregados em caso de perda de mais de $10 \%$ do peso original, como determina o código.

Quanto às saídas de emergência, constatou-se que a empresa dispõe de três saídas comuns, mas apenas uma permanece aberta. A maior distância a se percorrer até essa saída, em caso de emergência, é de 120 metros, bem maior que os 30 metros recomendados, para risco médio, pela norma. As outras duas saídas encontram-se trancadas mesmo durante a jornada de trabalho. Para diminuir a probabilidade de acidentes fatais, sugere-se destrancar todas as saídas. Após um estudo de rotas de fuga, constatou-se a necessidade de instalar três portas de emergência, todas abrindo para fora e com trava antipânico.

Outros graves problemas com relação ao risco de incêndio foram encontrados, tais como: falta de sistema de alarme com som distinto que possibilite avisar a todos os funcionários os casos de emergência; falta de sistema de iluminação de emergência; não há trabalhadores e vigias especialmente exercitados no manejo de material de luta contra o fogo; a empresa utiliza álcool em garrafas plásticas em vários setores de serviço de risco; há instalação elétrica com painel aberto e fiação improvisada presa na tubulação de gás natural e dentro do dique de óleo diesel; há cilindros de GLP armazenados em ambiente interno com pouca ventilação e grande quantidade de sucata armazenada em locais perigosos.

\section{Condições sanitárias e de conforto dos funcionários}

Os sanitários destinados aos funcionários da produção e transporte estão localizadas no edifício anexo em local muito afastado do ambiente de trabalho. Os sanitários não são submetidos a um processo eficiente de higienização, estão em péssimas condições de uso, mal ventilados, mal iluminados e não obedecem aos requisitos do Ministério da Saúde. A empresa também não possui vestiário em condições adequadas para os empregados.

A empresa está cadastrada no Programa de Alimentação do Trabalhador (PAT), instituído pelo Governo Federal, que tem por objetivo a melhoria da situação nutricional dos trabalhadores e dá direito a benefícios fiscais. A empresa fornece duas refeições para os empregados sem orientação de profissional competente para o preparo do cardápio com os valores nutritivos necessários. Um estudo detalhado demonstrou que o valor calórico das refeições atende apenas $70 \%$ das recomendações nutricionais estabelecidas pelo PAT. 


\section{Recomendações}

No intuito de contribuir na transformação da empresa em um ambiente agradável e seguro para todos, são apresentadas algumas recomendações:

- criação de uma política de segurança do trabalho e contratação de um técnico de segurança em tempo integral para compor o SESMT, e uma forte atuação da CIPA, a fim de garantir a saúde e a integridade do trabalhador no local de trabalho;

- cumprimento de normas e procedimentos de saúde e segurança do trabalhador por meio da elaboração de ordens de serviço e procedimentos operacionais;

- reformulação e implementação do PPRA;

- manutenção das condições da edificações garantindo proteção contra pragas e pequenos animais, proteções antiderrapantes e contra queda de altura, melhorias e higienização dos sanitários; melhoria nas condições de armazenagem dos alimentos na cozinha do refeitório e instalação de bebedouros com água potável próximos ao refeitório e ao setor de produção de alimentos;

- maior conforto nos postos de trabalho utilizando mobiliário adequado;

- registro, adequação e comprovação de eficácia dos EPIs;

- implantação de um programa de gerenciamento da frota visando treinamento, acompanhamento médico dos motoristas e manutenção preventiva;

- colocação de proteções nas partes móveis e elétricas de todas as máquinas;

- ter pelo menos um profissional técnico eletricista que possa garantir a manutenção preditiva, preventiva e corretiva em todas as instalações, elaborar um projeto global das instalações elétricas criando um padrão interno de qualidade, providenciar limpeza geral dos quadros elétricos e equipamentos, avaliar as condições de aterramento e a colocação de pára-raio no prédio;

- investir em proteção contra incêndio e explosões, realizar treinamento dos funcionários no uso de extintores e providenciar saídas de emergência;

- instalar sinalização sonora como dispositivo de segurança de máquinas e equipamentos, além de sinalização visual definindo um padrão de cartazes com alerta sobre os riscos existentes;

- melhoria da sinalização do piso, identificando os corredores de circulação e delimitando as áreas de armazenagem. Esta medida contibui para reduzir o risco de acidentes com a empilhadeira e o de incêndio em áreas obstruídas por paletes.

\section{Conclusão}

$\mathrm{O}$ atendimento às normas de segurança e saúde do trabalho proporcionará benefícios não somente aos funcionários como à própria empresa, tais como: economia de energia elétrica 
proporcionada pela manutenção e revisão da subestação e correção de fator de potência; economia de gás com a introdução de proteção em equipamentos visando isolamento térmico e segurança da operação; melhoria da qualidade do produto com a introdução de medidas de higiene; assiduidade ao trabalho com a realização de exames periódicos preventivos que proporcionarão saúde e bemestar aos trabalhadores; e redução nos custos referentes a causas trabalhistas e adicional de insalubridade com a eliminação ou minimização das situações de risco.

$\mathrm{O}$ atendimento à regulamentação é apenas uma das etapas de um processo de gestão que se inicia com a conscientização da necessidade de manter a qualidade para a competitividade e a conseqüente permanência no mercado. Uma gestão comprometida com a segurança do trabalhador, a qualidade e o bom relacionamento com a sociedade e o meio ambiente contribuem para melhorar a imagem da empresa facilitando a decisão de compra de clientes e consumidores.

\begin{abstract}
This work presents a study of safety and health in the workplace at a small food and beverage manufacturing plant in Rio de Janeiro, Brazil. Inspections, interviews with supervisors and employees, and qualitative evaluations identified the highest priority sectors to be examined for physical, chemical, biological, ergonomic and accident hazards. The specific areas of examination were manufacturing and employee facilities, fire prevention and control systems, physical and ergonomic hazards of the manufacturing process, and their level of conformance with pertinent government codes and standards. Conclusions and recommendations were presented aiming to transform the plant into a safe workplace.
\end{abstract}

Key words: safety, quality of life, occupational hazards.

\title{
11. Referências
}

ANUÁRIO BRASILEIRO DE PROTEÇÃO 2004. Novo Hamburgo : MPF Publicações, 2004. [Publicação anual da Revista Proteção].

ARAÚJO, Giovanni M. Normas regulamentadoras comentadas. 4. ed. Rio de Janeiro, 2003. 2 v.

BRASIL. Ministério da Agricultura e do Abastecimento. Lei no 8.918, de 14 de julho de 1994. Dispõe sobre a padronização, a classificação, o registro, a inspeção, a produção e a fiscalização de bebidas. D.O.U., Brasília, 05/09/1997. Disponível em: <http://masrv60.agricultura.gov.br/html/leis.asp?lei=8918>. Acesso em: 18 abr. 2004.

BRASIL. Ministério da Saúde. Secretaria de Vigilância Sanitária. Portaria no 326, de 30 de julho de 1997. Regulamento Técnico sobre as Condições Higiênico-Sanitárias e de Boas Práticas de Fabricação para Indústrias de Alimentos. D.O.U, Brasília, 01.08.97. Seção I. Disponível em: <http://www.anvisa.gov.br/ legis/portarias/326_ 97.htm>. Acesso em: 17 fev. 2004.

RAPID UPPER LIMB ASSESSMENT TOOL (RULA). Disponível em: <http://www. ergonomics.co.uk/ Rula/Ergo/>. Acesso em: 31 maio 2004. 